\title{
Congestive cardiomyopathy in a family of Becker's X-linked muscular dystrophy
}

\author{
B. C. KatiYar \\ M.D., M.R.C.P.(Lond.), F.R.C.P.(Edin) \\ S. MISRA \\ P. N. Somani \\ M.D. \\ A. M. Chaterji \\ F.R.C.P. (Glasg.), D.T.C.D. (Wales)

\begin{abstract}
Division of Neurology, Department of Medicine, Institute of Medical Sciences, Banaras Hindu University, Varanasi 221005, India
\end{abstract}

\begin{abstract}
Summary
The dissociation of gross congestive cardiomyopathy and muscle disease in different members of a family affected with Becker's benign X-linked muscular dystrophy is described. The possibility that cardiomyopathy and muscular dystrophy may be the expressions of the same mutant gene has been suggested.

\section{Introduction}

On the assumption that hypertrophic obstructive cardiomyopathy (HOCM) may be the cardiac manifestation of a general myopathy, Hootsmans and Meerschwam (1971) investigated twenty-three patients with HOCM and found electromyographic evidence of skeletal myopathy in fifteen. In support of these observations an interesting family is now reported.
\end{abstract}

\section{Materials and methods}

Five members of a family affected with Becker's benign $\mathrm{X}$-linked muscular dystrophy were the subjects of this study. The details of the pedigree are shown in Fig. 1.

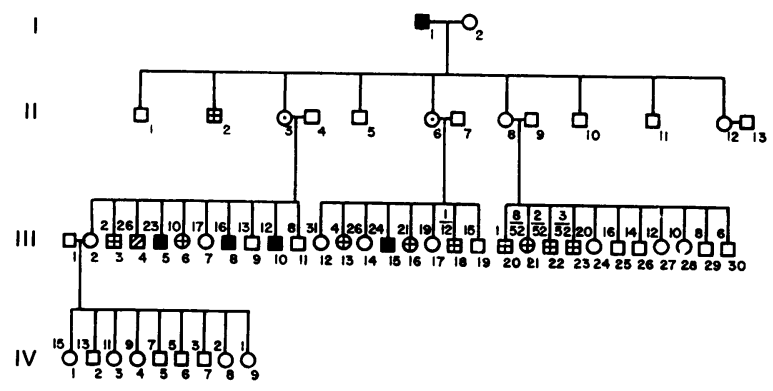

FIG. 1. Pedigree of the affected family. Age $\square$ No. $\bigcirc$, Unaffected male, female; $\mathbb{Z}$, Cardiomyopathy with hypertrophied calf muscle;, affected male; $\odot$, carrier female; $\oplus, \oplus$, dead male, female.

Correspondence: Dr B. C. Katiyar, A-2, New Medical Enclave, Banaras Hindu University, Varanasi 221005, India.
All the patients were examined clinically and the individual muscles were graded according to the MRC specifications (1943). The tests performed included determination of serum creatine phosphokinase (CPK) levels (Hughes, 1962), electrocardiography, chest X-ray, muscle biopsy and electromyography.

Electromyographic studies were done with a twochannel Medicor Electromyograph. Continuous records were obtained on a running photographic film during minimal and maximal volition at a sweep speed of $1 \mathrm{msec} / \mathrm{mm}$ and amplitude of $100 \mu \mathrm{V} / \mathrm{mm}$. Both the patients and the controls were examined by the same concentric needle electrode (Buchthal, Guld and Rosenfalck, 1954). The four quadrant? method was used for sampling of the muscles. The room temperature was kept constant at $27^{\circ} \mathrm{C}$ so that the effect of varying temperature might not alter the duration of motor unit potential (MUP) and the percentage of the polyphasic waves (Buchthal and Pinelli, 1951). The mean of twenty different action potentials from each sample was utilized for final evaluation of duration and amplitude of MUP. The potentials having five or more deflections across the base line were labelled polyphasic and were not included in the determination of mean duration and amplitude of MUP. For accuracy of calculation the film was projected on the screen giving a twelve-fold enlargement. The proximal muscles were selected for electromyography because clinically the weakness was most manifest in these muscles.

\section{Results}

The data on skeletal muscle and cardiac involvement are summarized in Tables 1 and 2.

One of the patients (III-4) presented with cardiomyopathy (Figs. 2 and 3 ) and slight hypertrophy of the right calf muscle with a difference of $2.3 \mathrm{~cm}$ in girth. Biopsy from the hypertrophied calf muscle showed variation of fibre size within the fascicles, thin fibres with prominent sarcolemmal nuclei and 
TABLE 1. Skeletal muscle involvement in affected members

\begin{tabular}{|c|c|c|c|c|c|c|c|c|c|}
\hline \multirow[b]{2}{*}{ Pedigree no. } & \multirow{2}{*}{$\begin{array}{c}\text { Age } \\
\text { (years) }\end{array}$} & \multirow{2}{*}{$\begin{array}{c}\text { Age at } \\
\text { onset }\end{array}$} & \multicolumn{3}{|c|}{ Muscle weakness* } & \multirow{2}{*}{$\begin{array}{l}\text { Calf } \\
\text { hyper- } \\
\text { trophy }\end{array}$} & \multirow[b]{2}{*}{ Disability } & \multirow{2}{*}{$\begin{array}{c}\text { Serum } \\
\text { CPK } \dagger \\
(\mu \mathrm{mol} / \\
\mathrm{ml} / \mathrm{hr})\end{array}$} & \multirow{2}{*}{$\begin{array}{c}\text { Dystrophic } \\
\text { change in } \\
\text { muscle } \\
\text { biopsy }\end{array}$} \\
\hline & & & Face & Shoulder & Pelvic & & & & \\
\hline $\mathrm{I}-1_{+}^{+}$ & 67 & $? 30$ & $?$ & $?$ & $?+$ & $?$ & Minimal & Not done & Not done \\
\hline III-4 & 26 & 24 & 0 & 0 & 0 & + & Nil & $2 \cdot 06$ & Present \\
\hline III-5 & 23 & 9 & 0 & + & $+t$ & ++ & Nil & $24 \cdot 20$ & Present \\
\hline III-8 & 16 & 8 & 0 & ++ & +++ & +++ & Minimal & $2 \cdot 30$ & Present \\
\hline III-10 & 12 & 10 & 0 & +++ & $+t+t$ & $++t$ & Minimal & $12 \cdot 00$ & Present \\
\hline III-15 & 24 & 9 & 0 & 0 & + & - & Minimal & Not done & Not done \\
\hline
\end{tabular}

* Graded from normal $(0)$ to very weak $(++++)$.

$\dagger$ Normal CPK value in serum: $0 \cdot 39-3 \cdot 8 / \mu \mathrm{mol} / \mathrm{ml} / \mathrm{hr}$.

\$ Patient deceased, information obtained from relatives.

TABLE 2. Cardiac involvement in affected members

\begin{tabular}{|c|c|c|c|}
\hline Pedigree no. & Clinical & X-ray & ECG \\
\hline $\mathrm{I}-1$ & Data not available & & \\
\hline III-4 & $\begin{array}{l}\text { Extra systole, heart } \\
\text { failure } \\
\text { Cardiomegaly }\end{array}$ & Cardiomegaly & $\begin{array}{l}\text { Ventricular extrasystole. } \\
\text { Left ventricular preponderance. } \\
\text { Non-specific } T \text { wave changes }\end{array}$ \\
\hline III-5 & Normal & Normal & Inverted $T$ waves in $V_{5-6}$ \\
\hline III-8 & Extrasystole & Normal & $\begin{array}{l}\text { Ventricular extrasystole } \\
\text { Prominent } R \text { waves in } V_{1-2}\end{array}$ \\
\hline III-10 & Normal & Normal & Prominent $R$ waves in $V_{1}$ \\
\hline III-15 & Normal & Not done & Not done \\
\hline
\end{tabular}

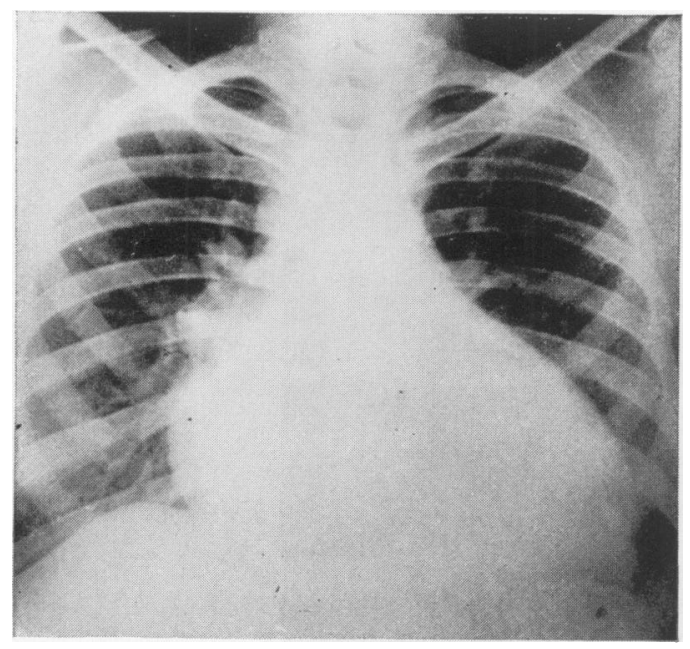

FIG. 2. Chest X-ray of patient No. III-4 showing cardiomegaly. single fibres undergoing necrosis (Figs. 4 and 5). In contrast to this patient, the other affected members (I-1, III-5, III-8, III-10, III-15) had varying grades of skeletal muscle weakness without any evidence of cardiac involvement clinically or radiologically, although they had electrocardiographic abnormalities in the form of $R$ and $T$ wave changes in the right precordial leads. None of them had any significant disability. All the patients in whom muscle biopsy was done had histological evidence of muscular dystrophy in the form of variation in the fibre thickness, prominent and centrally placed sarcolemmal nuclei, areas of necrosis and fatty infiltration. Electromyography revealed myopathic pattern in all the patients (Table 3 ).

\section{Discussion}

In view of the relatively late onset and benign character of the dystrophic process in the affected males and considering the fact that their maternal grandfather survived long enough to have children, 


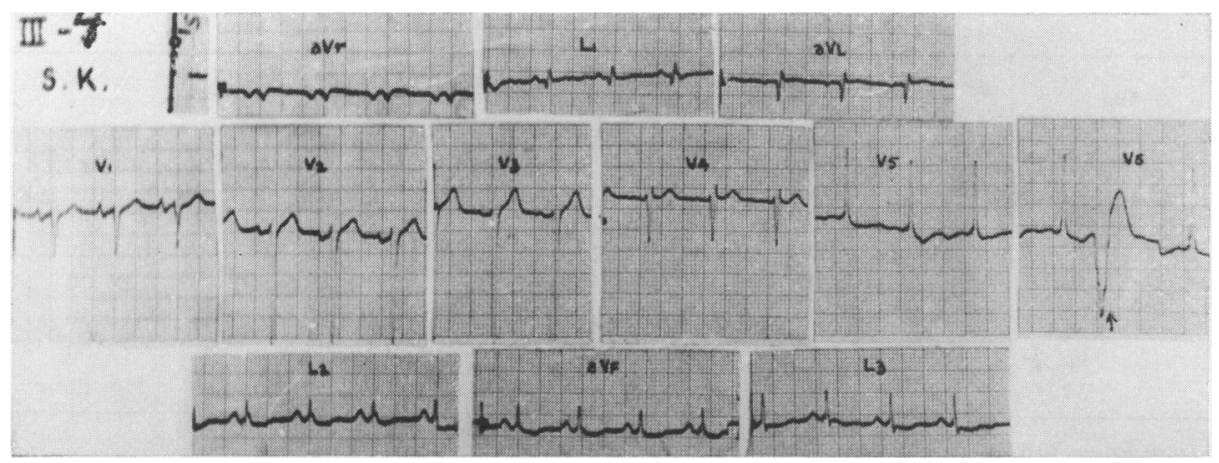

FIG. 3. Electrocardiogram of patient No. III-4 showing ventricular extrasystole and non-specific $T$ wave changes.

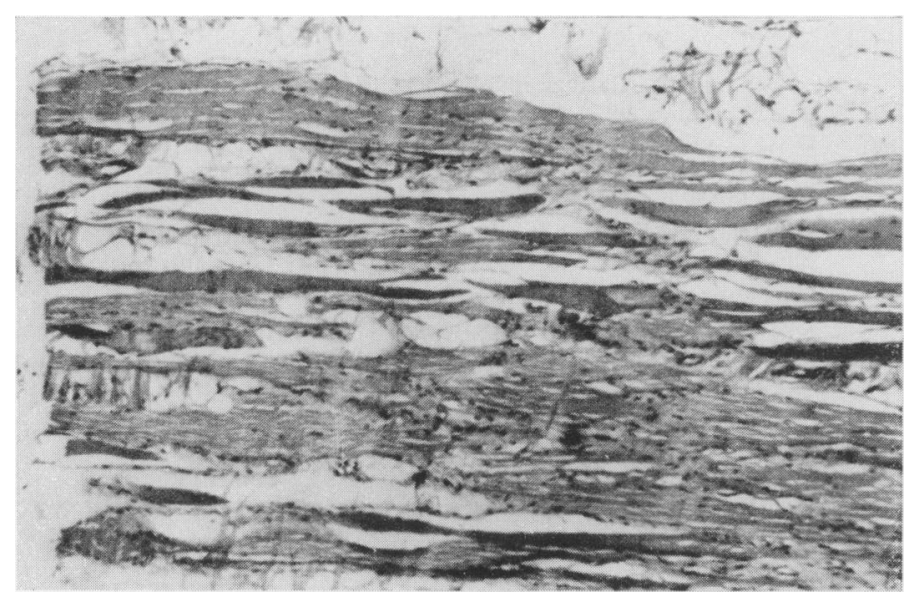

FIG. 4. Longitudinal section from the calf muscle of patient No. III-4 showing myopathic changes $(\times 60)$.

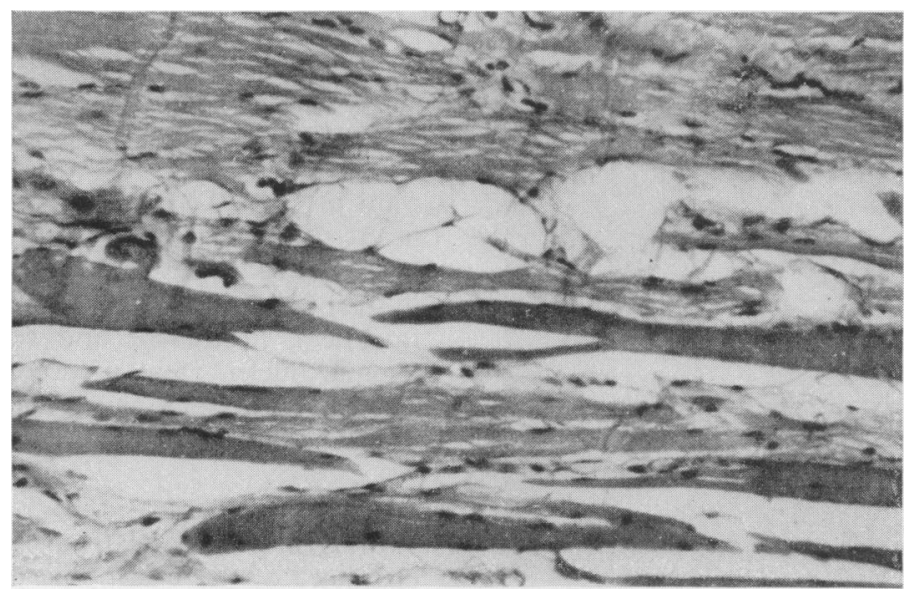

FIG. 5. Longitudinal section from the calf muscle of patient No. III-4 showing myopathic changes $(\times 150)$. 
TABLE 3. Electromyographic studies in the affected members of the family

\begin{tabular}{|c|c|c|c|c|c|c|c|c|c|c|}
\hline \multirow[b]{2}{*}{ Case no. } & \multicolumn{2}{|c|}{ Deltoid } & \multicolumn{2}{|c|}{ Biceps } & \multicolumn{2}{|c|}{ Triceps } & \multicolumn{2}{|c|}{ Quadriceps } & \multicolumn{2}{|c|}{ Gluteus maximus } \\
\hline & D & $\mathbf{P}$ & D & $\mathbf{P}$ & D & $\mathbf{P}$ & D & $\mathbf{P}$ & D & $\mathbf{P}$ \\
\hline $\begin{array}{l}\text { Controls } \\
\text { III-4 } \\
\text { III-5 } \\
\text { III-8 } \\
\text { III-10 } \\
\text { III-15 }\end{array}$ & $\begin{array}{l}6 \cdot 8 \pm 0 \cdot 97 \\
5 \cdot 0 \\
3 \cdot 6 \\
5 \cdot 4 \\
3 \cdot 9 \\
4 \cdot 0\end{array}$ & $\begin{array}{l}<10 \\
<10 \\
<15 \\
<10 \\
<15 \\
<10\end{array}$ & $\begin{array}{l}7 \cdot 2 \pm 0 \cdot 86 \\
4 \cdot 2 \\
4 \cdot 2 \\
4 \cdot 5 \\
4 \cdot 4 \\
4 \cdot 8\end{array}$ & $\begin{array}{l}<10 \\
<10 \\
<15 \\
<10 \\
<10 \\
<10\end{array}$ & $\begin{array}{l}6 \cdot 8 \pm 0 \cdot 78 \\
4 \cdot 4 \\
4 \cdot 4 \\
5 \cdot 7 \\
4 \cdot 7 \\
5 \cdot 0\end{array}$ & $\begin{array}{l}<10 \\
<10 \\
<15 \\
<10 \\
<10 \\
<10\end{array}$ & $\begin{array}{l}7 \cdot 0 \pm 0 \cdot 58 \\
3 \cdot 4 \\
2 \cdot 6 \\
2 \cdot 9 \\
3 \cdot 7 \\
3 \cdot 2\end{array}$ & $\begin{array}{l}<10 \\
<10 \\
<20 \\
<15 \\
<15 \\
<15\end{array}$ & $\begin{array}{l}6 \cdot 7 \pm 0 \cdot 62 \\
3 \cdot 0 \\
2 \cdot 0 \\
3 \cdot 0 \\
4 \cdot 1 \\
3 \cdot 0\end{array}$ & $\begin{array}{l}<10 \\
<10 \\
<20 \\
<20 \\
<15 \\
<25\end{array}$ \\
\hline
\end{tabular}

Full interference pattern was observed in all the muscles in all the cases.

$\mathrm{D}$, Duration of motor unit potential; $\mathrm{P}$, polyphasic action potential $\%$.

it is felt that the family is affected with Becker's benign X-linked muscular dystrophy. Occurrence of cardiomyopathy in one member of this family, who also had evidence of latent muscular dystrophy, seems to be more than a coincidence. Similar dissociation of muscular dystrophy and cardiomyopathy in different members of a family was also observed by Hootsmans and Meerschwam (1971) in two of their twenty-three patients with HOCM. These facts point to the possibility that idiopathic cardiomyopathy may be an expression of the same mutant gene which is responsible for muscular dystrophy. In view of this, the authors strongly feel that all the patients with idiopathic cardiomyopathy and their relatives should be thoroughly investigated for the presence of primary skeletal muscle disease which may be minimal or clinically absent. It is likely to be missed unless specifically searched for.

\section{Acknowledgments}

We thank Dr V. Lalitha and Mr N. K. Banerjee of K.E.M. Hospital, Bombay, for doing the histopathological studies and CPK estimations.

\section{Addendum}

The patient (III-10) who initially had mild skeletal muscular dystrophy was seen recently in gross congestive heart failure with cardiomegaly mimicking the cardiac status of III-4. The present electrocardiogram showed left ventricular hypertrophy with non-specific $\mathrm{T}$ wave changes.

\section{References}

Buchthal, F., Guld, C. \& Rosenfalck, P. (1954) Action potential parameters in normal human muscle and their dependence on physical variables. Acta physiologica scandinavica, 32, 200.

Buchthal, F. \& Pinelli, P. (1951) Action potential analysis in normal muscle. Acta physiologica scandinavica (Suppl. 89), 13.

Hootsmans, W.J.M. \& Meerschwam, I.S. (1971) Electromyography in patients with hypertrophic obstructive cardiomyopathy. Neurology, 21, 810.

Hughes, B.P. (1962) A method for the estimation of serum creatine kinase and its use in comparing creatine kinase and aldolase activity in normal and pathological sera. Clinica chimica acta, 7, 597.

MRC War Memorandum No. 7 (1943) Aids to the Investigation of Peripheral Nerve Injuries, Second edn. H.M. Stationery Office, London. 